\title{
LEFT VENTRICULAR DIASTOLIC FILLING IN YOUNG PERSONS WITH TYPE 1 DIABETES MELLITUS
}

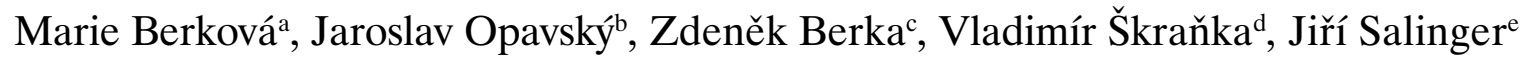

\author{
a $1^{\text {st }}$ Department of Internal Medicine, Palacký University Hospital, Olomouc, Czech Republic \\ ${ }^{b}$ Department of Physiotherapy and Pain Management, Faculty of Physical Culture, Palacký University, Olomouc \\ c $2^{\text {nd }}$ Department of Internal Medicine, Palacký University Hospital \\ d Department of Internal Medicine, Military Hospital, Olomouc \\ e Department of Biomechanics and Engineering Cybernetics, Faculty of Physical Culture, Palacký University
}

Received: April 20, 2003

Key words: Diabetes mellitus / Left ventricular diastolic filling / Echocardiography

The purpose of this study was to evaluate the influence of diabetes mellitus on left ventricular function. Using Doppler echocardiography we examined a group of 49 young (20-32 years old) persons with type 1 diabetes mellitus and a group of healthy age-matched men and evaluated the parameters of diastolic filling of the left ventricle $(\mathrm{LV})$. We found significant differences in peak velocity of early filling of the left ventricle $((70.07 \pm 10.84 \mathrm{vers}$. $\left.78.2 \pm 10.59 \mathrm{~cm} . \mathrm{s}^{-1}, \mathrm{p} \pm 0.01\right)$, peak velocity of late diastolic filling of $\mathrm{LV}\left(\mathrm{A}=47.74 \pm 11.6\right.$ vers. $43.15 \pm 7.48 \mathrm{~cm} . \mathrm{s}^{-1}$, $\mathrm{p} \leq 0.027)$, ratio $\mathrm{E} / \mathrm{A}(1.53 \pm 0.4$ vers. $1.84 \pm 0.33)$, time velocity integral of peak $\mathrm{E}(\mathrm{TVIE}=0.083 \pm 0.014$ vers. $0.1 \pm 0.022 \mathrm{~m}, \mathrm{p} \leq 0.001)$, time velocity integral of peak A (TVIA $=0.039 \pm 0.011$ vers. $0.037 \pm 0.012 \mathrm{~m}, \mathrm{p} \leq 0.3)$, ratio TVIE/TVIA (2.3 \pm 0.73 vers. $2.9 \pm 0.9, \mathrm{p} \leq 0.001)$, time $\mathrm{E}(204.4 \pm 31.59$ vers. $198.4 \pm 19.09 \mathrm{~ms}, \mathrm{p} \leq 0.27)$, time A $(126.9 \leq 23.0$ vers. $113.5 \pm 15.59 \mathrm{~ms}, \mathrm{p} \leq 0.002)$, time $\mathrm{E} /$ time $\mathrm{A}(1.64 \pm 0.3$ vers. $1.76 \pm 0.22, \mathrm{p} \leq 0.039)$ and duration of isovolumic relaxation period (IVRT $=88.2 \pm 10.8$ vers. $71.13 \pm 8.4 \mathrm{~ms}, \mathrm{p} \leq 0.0001$ ). Despite significant differences all the results were in the range of values for the healthy population. However in detailed analysis we found that the values measured in young (20-32 years old) persons with type 1 diabetes mellitus corresponded with diastolic parameters of healthy men of the age of 50 years and more. Thus, diabetes mellitus can influence the relaxation properties of the left ventricle.

\section{INTRODUCTION}

Diabetes mellitus is a chronic disease with increased cardiovascular morbidity and mortality. Its incidence is rising and it is becoming a severe health problem mainly in civilized countries ${ }^{1,2,3}$. In the Czech Republic, approximately half a million persons with diabetes mellitus have been diagnosed, of whom about 10 percent are type 1 diabetics.

The severity of type 1 diabetes mellitus is underlined by the fact, that it originates mostly at an early age, often in childhood, is an integral part of the patient's life and leads to many complications which may be fatal at advanced stages.

Since diabetes mellitus affects all cells, diabetes complications may involve almost all organs. Therefore, diabetic patients are examined regularly for possible development of diabetic nephropathy, retinopathy and peripheral neuropathy. However, little attention has been paid to studies of heart function. The more frequent incidence of heart failure in diabetics even in the absence of ischaemic heart disease, valvular heart disease or another disorder outside diabetes, leads to the presumption that diabetes mellitus unfavourably affects the heart muscle by its complications.
This hypothesis was tested first experimentally and then in studies dealing with experimentally-induced diabetes in rats showing cytochemical, cytological and histological changes of heart muscle ${ }^{4,5,6}$. These changes affect the development of microangiopathy of the heart muscle, pathology of the cardiomyocytes and increased fibrosis of the interstitium leading to reduce myocardium compliance and to pathological involvement of the cardiac autonomic nervous system ${ }^{7-19}$. Cardiac autonomic neuropathy is manifested by altered function of the sinoatrial node, decreased parasympathetic function, then sympathetic function. This can be shown by examination of autonomic functions using spectral analysis of heart rate variability ${ }^{20}$.

Initial changes in cell metabolism, structure and function of myocardium are obscure on clinical examination and at an early phase of the disease patients do not show signs of cardiac disorder ${ }^{21,22}$. However, echocardiographic or radio-isotope examination of functional parameters of the left ventricle can show clinically latent abnormalities even in fully asymptomatic patients ${ }^{21,22}$. Some authors found hypercontractility of the left ventricle at the beginning of diabetes development, subsequently followed by a disorder of diastolic function and then by decrease in systolic indices of the left ventricular function ${ }^{21,22}$. 
Phases of diastolic function:

Diastole is divided into four phases ${ }^{23,24,25}$ :

1. Isovolumic relaxation phase (left ventricular pressure drops after aortic closure but before mitral opening)

2. Rapid filling phase (peak E on Doppler echocardiography, a passive phenomenon, which depends on the pressure difference between left atrium and left ventricle that drives blood into the left ventricle)

3. Diastasis (only relatively little filling occurs)

4. Atrial contraction phase (peak A on Doppler echocardiography, depends on active atrial contraction).

The diastolic function is determined by both the intrinsic myocardial and extrinsic factors. Intrinsic myocardial factors, influencing diastolic properties of the left ventricle include: myocardial relaxation, atrial contraction, viscoelastic properties and myocardial stiffness.

Extrinsic (loading factors) include: preload and afterload, vascular volume, heart rate, breathing, aging.

Two main diastolic properties influence the Doppler echocardiographic pattern of left ventricle filling: relaxation and compliance of left ventricle.

When relaxation of left ventricle (LV) is slowed, either by normal aging or cardiac disease, the transmitral pressure gradient in early diastole decreases and a greater proportion of filling occurs at atrial contraction. A decrease in compliance produces the opposite results, as the associated increase in filling pressure causes earlier mitral valve opening, larger early diastolic transmitral pressure gradient and increased proportion of filling in early diastole (pseudonormalization of the flow) ${ }^{26}$. The Doppler examination of pulmonary venous flow is perfomed to differentiate the normal pattern of left ventricle filling from pseudonormalization.

\section{THE AIM OF THE STUDY}

The aim of the study was to follow-up the occurence of preclinical left ventricular filling abnormalities in young persons with diabetes and thus to contribute to better knowledge of heart disease related to diabetes and to better understanding of increased cardiac morbidity and mortality in diabetics.

\section{METHODS}

The project was designed as a non-invasive controlled study using echocardiography.

Echocardiographic examinations were performed in the echocardiography laboratory of the University Hospital Olomouc, by means of echocardiographic machines Ultramark 9 HDI with a mechanical probe and Toshiba SSW 380 with electronic probe.

A series of patients under study consisted of thoroughly selected young cardiac-asymptomatic patients with type 1 diabetes mellitus, without other associated disease and complying with the entering criteria of the study. The control group consisted of healthy age- and sex-matched individuals.

We have designed a basic method, according to which a patient entering our study was examined. The study was performed with appproval of the Ethic Committee of the Faculty of Medicine, Palacký University in Olomouc and according to Helsinki Declaration.

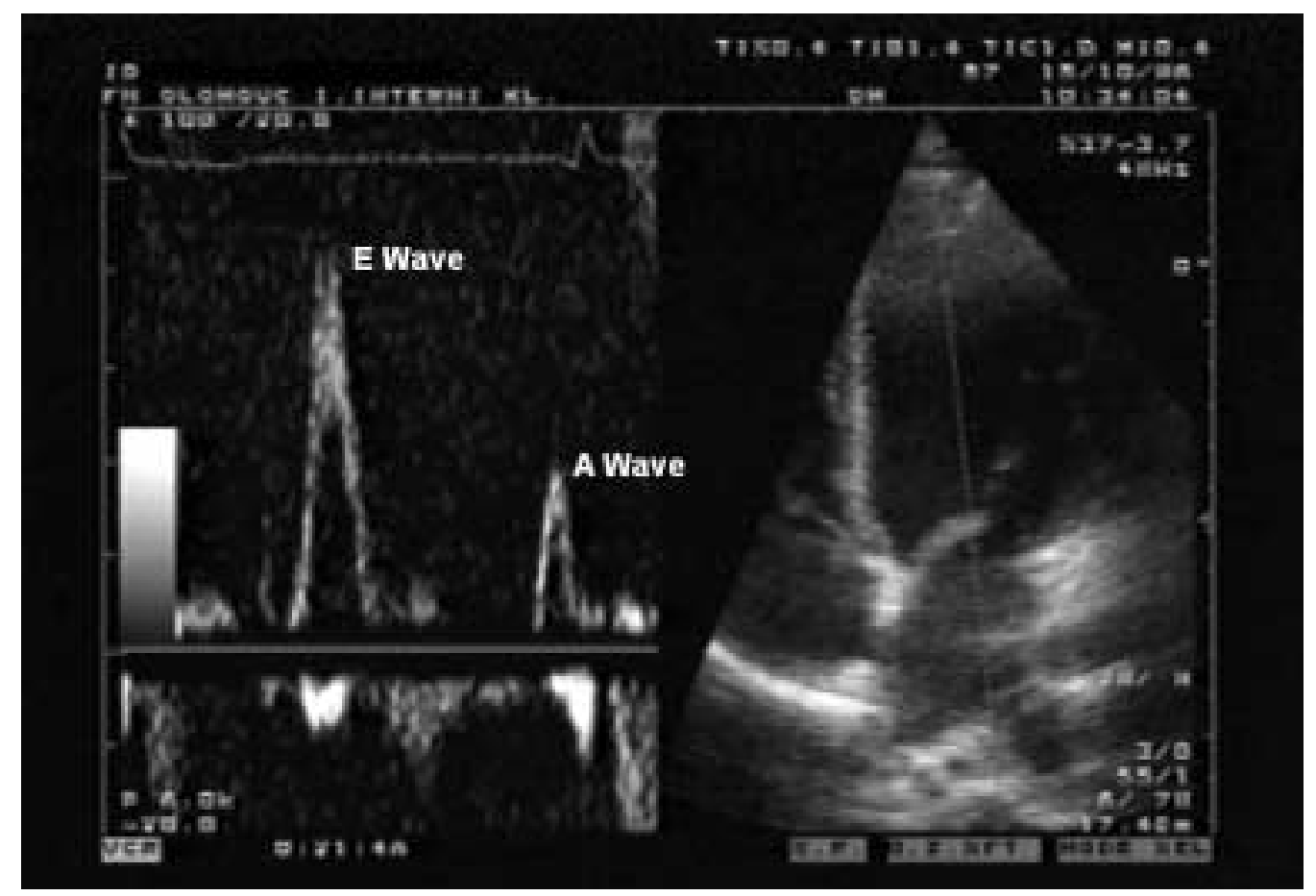

Fig. 1. Pulsed Doppler imaging of transmitral flow pattern. 
Inclusion criteria for the study:

Sex: male

Age: $20-32$ years

Body mass index: 20-25

Diabetes mellitus, type 1

Therapy: insulin treatment (without any other therapy influencing cardiac function)

Exclusion of any concomitant disease

Normal biochemical and haematological laboratory screening /except glycaemia/ (see Fig. 2)

Normal systolic function (ejection fraction of the left ventricle $\geq 60 \%$, without regional hypokinesis, dyskinesis or akinesis)

Using echocardiography we evaluated, in addition to the routinely followed-up parameters, the indices of left ventricular diastolic filling. When echocardiography revealed heart disorder, focal kinetics disorder or another pathological finding not related to possible involvement of the heart muscle in diabetes, the patient was excluded from the study. Coronary artery disease was excluded by the lack of history of myocardial disease, electrocardiographic changes and echocardiography performance. (Invasive examination of coronary arteries, i.e. invasive coronarography could not be applied to healthy and asymptomatic volunteers for ethical reasons). To exclude the influence of extrinsic factors all patients were normotensive and all values were calculated from three measurements gained during three heart cycles at the end of quiet exspirium. Statistical analysis was carried out, using Mann Whitney's test to compare mean values of the groups. Table 1 shows relevant parameters of left diastolic ventricular filling.

\section{RESULTS}

A total of 49 young (mean age $25.4 \pm 3.6$ years) cardiac asymptomatic type 1 diabetic men without any concomitant disease and 40 age- and sex-matched healthy subjects were studied by echocardiography M-mode, two dimensional echo and transmitral blood flow pattern was evaluated by Doppler echocardiography. The pseudonormalization of Doppler transmitral flow pattern was excluded by history of young healthy men, measurement of pulmonary vein flow pattern and Valsalva maneuver. No studied subject showed signs of pseudonormalization. Table 2 shows the results of examination.

The results show significant differences especially in ratio E/A, TVIE/TVIA and duration of isovolumic relaxation period, which is a sensitive parameter of relaxation. However all alterations in measured parameters are very small and within normal range comparing with the whole adult healthy population. In detailed analysis measured values of our 20-30 years old diabetics correlate with the findings in healthy men of the age of 50 years in other studies ${ }^{27,28}$.

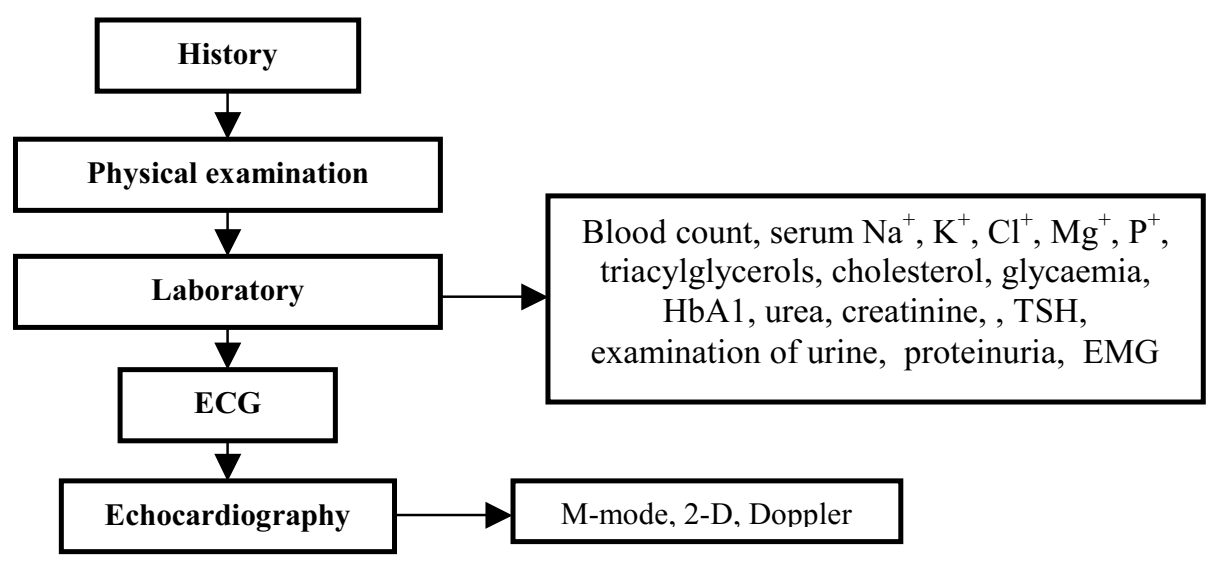

Fig. 2. Scheme of examination of patient in the study.

Table 1. Left ventricle diastolic filling parameters: Abbreviation (Unit)/Full description.

\begin{tabular}{|l|l|}
\hline E $(\mathrm{cm} / \mathrm{s})$ & peak velocity of early left ventricular diastolic filling \\
\hline A $(\mathrm{cm} / \mathrm{s})$ & peak velocity of late left ventricular diastolic filling \\
\hline E/A & ratio of early and late left ventricular diastolic filling \\
\hline TVIE $(\mathrm{m})$ & time velocity integral of early left ventricular filling \\
\hline TVIA $(\mathrm{m})$ & time velocity integral od late left ventricular filling \\
\hline TVIE/TVIA & ratio of time velocity integrals of early and late filling of LV \\
\hline time E $(\mathrm{ms})$ & duration of early left ventricular diastolic filling \\
\hline time A $(\mathrm{ms})$ & duration of late ventricular diastolic filling \\
\hline timeE/time A & ratio of duration of early and late ventricular filling \\
\hline deceler.time $(\mathrm{ms})$ & deceleration time of early left ventricular filling \\
\hline IVRT $(\mathrm{ms})$ & duration of isovolumic relaxation period \\
\hline
\end{tabular}


Table 2. Assessed values of left ventricle diastolic filling pattern.

\begin{tabular}{|l|l|l|l|}
\hline $\begin{array}{l}\text { Parameters of left diastolic } \\
\text { filling of LV }\end{array}$ & \multicolumn{1}{|c|}{$\begin{array}{c}\text { Diabetics } \\
(\mathrm{n}=49)\end{array}$} & \multicolumn{1}{|c|}{$\begin{array}{c}\text { Controls } \\
(\mathrm{n}=40)\end{array}$} & \\
\hline $\mathrm{E}(\mathrm{cm} / \mathrm{s})$ & $70.07 \pm 10.84$ & $78.2 \pm 10.95$ & $\mathrm{p} \leq 0.01$ \\
\hline $\mathrm{A}(\mathrm{cm} / \mathrm{s})$ & $47.74 \pm 11.60$ & $43.15 \pm 7.48$ & $\mathrm{p} \leq 0.027$ \\
\hline E/A & $1.53 \pm 0.4$ & $1.84 \pm 0.33$ & $\mathrm{p} \leq 0.0002$ \\
\hline TVIE $(\mathrm{m})$ & $0.083 \pm 0.014$ & $0.1 \pm 0.022$ & $\mathrm{p} \leq 0.001$ \\
\hline TVIA $(\mathrm{m})$ & $0.039 \pm 0.011$ & $0.037 \pm 0.012$ & $\mathrm{p} \leq 0.3$ \\
\hline TVIE/TVIA & $2.30 \pm 0.73$ & $2.90 \pm 0.90$ & $\mathrm{p} \leq 0.001$ \\
\hline Time E $(\mathrm{ms})$ & $204.4 \pm 31.59$ & $198.4 \pm 19.09$ & $\mathrm{p} \leq 0.27$ \\
\hline Time A $(\mathrm{ms})$ & $126.9 \pm 23.0$ & $113.5 \pm 15.59$ & $\mathrm{p} \leq 0.002$ \\
\hline Time E/Time A & $1.64 \pm 0.30$ & $1.76 \pm 0.22$ & $\mathrm{p} \leq 0.039$ \\
\hline Deceler time E $(\mathrm{ms})$ & $117.1 \pm 20.03$ & $117.2 \pm 16.6$ & $\mathrm{p} \leq 0.97$ \\
\hline IVRT $(\mathrm{ms})$ & $88.2 \pm 10.8$ & $71.13 \pm 8.4$ & $\mathrm{p} \leq 0.0001$ \\
\hline
\end{tabular}

\section{DISCUSSION}

In the present study significant difference for diastolic filling of the left ventricle was found between young insulin dependent diabetic patients and a control group of healthy men of the same age. Differences in left ventricular diastolic filling could not be attributed to abnormal systolic function, since patients with cardiac conditions which impaire diastolic filling had been excluded.

The entity of diabetic cardiomyopathy was first proposed by Rubler et al. (1972) ${ }^{29}$ on the basis of postmortem studies and later other experts described many histological and histochemical abnormalities in diabetic myocardium, especially extensive perivascular and interstitial fibrosis, endothelial proliferation, subendothelial hyaline thickening with PAS-positive material in the vessel wall and capillary microaneurysms. Decreased activity of myosin ATP-ase, a shift in myosine enzyme distribution, alterations in a variety of $\mathrm{Ca}$ fluxes and changes in responses to alpha and beta adrenergic and cholinergic stimulation have been recognized in myocardiocytes. Subsequently abnormalities in both systolic and diastolic function in diabetic subjects have been demonstrated in animal and human studies. Hamby et al. ${ }^{30}$ reported a significantly increased prevalence of diabetes in idiopathic cardiomyopathy unassociated with large vessel coronary artery disease. Increasing attention has been focused recently on the importance of left ventricular diastolic dysfunction in the aetiology of congestive heart failure with intact systolic function. Diastolic abnormalities have been noted to precede systolic dysfunction in many instances ${ }^{22}$.

Several studies reported diminished ventricular compliance at cardiac catheterization, subsequently echocardiography methods were introduced for evaluation of diastolic function ${ }^{22}$. M-mode and two-dimensional echocardiography was first used and then Doppler echocardiography ${ }^{31}$ to evaluate diastolic parameters.
Doppler echocardiography interrogation of mitral flow patterns have been previously shown to correlate well with results of catheterization and radionuclide methods. Our study confirm the findings of several previous studies showing existence of small differences in diastolic filling between young persons with diabetes and age-matched healthy men. During the examination of the cardiac autonomic neuropathy using spectral analysis of heart rate variability, no dependency of the incidence of abnormalities of left ventricle diastolic filling on the incidence of the cardiac autonomic neuropathy has been shown. The Doppler echocardiography is a useful method for the follow-up of diastolic function of persons with diabetes. However, it is important to avoid technical pitfalls as beam misalighment, misplacement of sample volume, incorrect pulsed wave Doppler sample volume size, too high Doppler gain setting and failure to recognize the suboptimal Doppler spectral flow velocities. Recognizing the technical pitfalls and following the general sequence of the Doppler examination for diastolic evaluation can result in a complete and accurate Doppler evaluation of LV diastolic function.

\section{CONCLUSION}

Significant differences in the parameters of left ventricular diastolic filling between a group of young diabetics and a group of healthy age-matched men were found in this study. In detailed analysis assessed values of our 20-32 years old men with diabetes correlated with findings in healthy men of the age of 50 years in other studies ${ }^{27,28}$. These findings suggest that relaxation properties deteriorate in diabetics more rapidly than in healthy subjects.

These results contribute to better understanding of pathological process resulting in cardiac failure in diabetic patients and support the optimum therapeutic strategies. 


\section{REFERENCES}

1. Dries DL, Sweitzer NK, Drazner MH, Stevenson LW, Gersh BJ (2001) Prognostic impact of diabetes mellitus in patients with heart failure according to the etiology of left ventricular systolic dysfunction. JACC 38, 421-8.

2. Mokhad AH, Bowman BA, Ford ES, Vinicor F, Marks JS, Koplan JP. (2001) The continuing epidemics of obesity and diabetes in the United States. JAMA 286, 1195-9.

3. Harris MI, Glegal KM, Cowie CC. (1998) Prevalence of diabetes impaired fasting glucose and impaired glucose tolerance in U.S. adults: the Third National Health and Nutrition Examination Survey, 1988-1994. Diabetes Care 21, 518-24.

4. Anděl M. (2001) Komplikace diabetes mellitus. In: Diabetes mellitus a další poruchy metabolismu., 1. ed, Galén, 75-113.

5. Mahgoub MA, Abd-Elfattah AS. (1998) Diabetes mellitus and cardiac function. Mol Cell Biochem 180, 59-64.

6. Tanaka Y, Konno N, Kako KJ. (1992) Mitochondrial dysfunction observed in situ in cardiomycytes of rats in experimenal diabetes. Cardiovasc Res 26, 409-14.

7. Zhu-Xing Z, Zhou-Xiao-Peng Z, Xue-Li Z, Ci-Sheng Z, Yong-Fu Y. (1993) Streptozocin induced cardiomypathy in diabetic rat Chin Med J 106, 463-6.

8. Shehadeh A, Regan TJ. (1995) Cardiac consequences of diabetes mellitus. Clinical Cardiology 18, 301-5.

9. Minamato M, Shimizu M, Suematsu T, Sugihara N, Kita Y, Shimada T, Murakami T, Ohsato K, Konishi K, Takeda R. (1990) Early diastolic dysfunction of the left ventricle and its relation to histopathological findings in patients with diabetes mellitus. J Cardiol 20, 293-300.

10. Van Hoeven KH, Factor SM. (1990). A comparison of the pathological spectrum of hypertensive, diabetic and hypertensive-diabetic heart disease. Circ 82, 848-55.

11. Kawaguchi M, Techigawara M, Ishihata T, Asakura T, Saito F, Maehara K, Maruyama Y. (1997) A comparison of ultrastructural changes on endomyocardial biopsy specimens obtained from patients with diabetes mellitus with and without hypertension. Heart and Vessels 12, 267-74.

12. Thompson EW. (1988) Structural manifestations of Diabetic Cardiomyopathy in the rats and its reversal by insulin treatment. Am J Anatom 182, 270-82.

13. Giacomelli F, Wiener J. (1979) Primary myocardial disease in the diabetic mouse: an ultrastructural study. Lab Invest 40, 460-73.

14. Fein FS, Sonnenblick BH. (1994) Diabetic cardiomyopathy, Cardiovasc Drugs Ther 8, 65-73.
15. Blumenthal HT, Alex M, Goldenberg S. (1960) A study of lesions of the intramural coronary branches in diabetes mellitus. Arch Patol 70, 27-42.

16. Ledet T. (1968) Histological and histochemical changes in the coronary arteries of old diabetic patients. Diabetology 4, 268-72.

17. Ledet T. (1976) Diabetic cardiomyopathy: quantitative histological studies of the heart from young juvenile diabetics. Acta Pathol Microbiol Scand Sect A Pathol 84, 421-2.

18. Factor SM, Okun EM, Minase T. (1980) Capillary microaneurysm in the human diabetic heart. New Engl J Med 302, 384-8.

19. Sasváry F. (1995) Heart rate variability a marker of the vegetative activity. Noninvas Cardiol 4, 179-86.

20. Opavský J. (2002) Autonomní nervový system a diabetická autonomní neuropatie. Galén, $1^{\text {st }}$ ed., 163-78.

21. Chlumský J, Dvořáková L. (1994) Význam dopplerovské echokardiografie diabetiků I. typu. Vnitřní Lék 40, 499-501.

22. Raev DC. (1994) Which left ventricular function is impaired earlier in the evolution of diabetic cardiomyopathy? Diabetes Care 17, 633-9.

23. Hůla J, Boček P. (1998) Systolická a diastolická dysfunkce levé komory srdeční. Prakt Lék 78, 13-6.

24. Krzeminska-Pakula M, Kasprzak J. (1992) Doppler ultrasound evaluation of left ventricular diastolic function. Neinvaz kardiol 1, 263-6.

25. Vítovec M, Frídl P. (1990) Hodnocení diastolických funkcí levé komory pomocí pulsní dopplerovské echokardiografie. Vnitř Lék 36, 1011-7.

26. Meluzín J. (2002) Diastolická dysfunkce levé komory. In: Niederle Echokardiografie, Triton, Praha, 156-60.

27. Appleton CP, Hatle LK, Popp RL. (1988) Relation of transmitral flow velocity patterns to left ventricular diastolic function. New insights from a combined hemodynamic and Doppler echocardiographic study. JACC 12, 426.

28. Spirito P, Maron BJ. (1988) Influence of aging on Doppler echocardiographic indices of left ventriuclar diastolic function. $\mathrm{Br}$ Heart J 59, 672-9.

29. Rubler S, Dlugash J, Yuceoglu Y, Kumral T, Branwood AW, Grishman A. (1972) New type of cardiomyopathy associated with diabetic glomerulosclerosis. Am J Cardiol 30, 595-602.

30. Hamby RI, Zonereich S, Sherman L. (1974) Diabetic cardiomyopathy. J Am Med Assoc 229, 1749-54.

31. Annonu AK, Fattah AA, Mokhtar MS, Ghareeb S, Elhendy A. (2001) Left ventricular systolic and diastolic functional abnormalities in asymptomatic patients with non-insulin-dependent diabetes mellitus. J Am Soc Echocardiography 14, 885-91. 